\title{
The effect of ethnicity on semen analysis and hormones in the infertile patient
}

Nahid Punjani ${ }^{1}$; Madhur Nayan² ${ }^{2}$ Keith Jarvi ${ }^{2}$; Kirk Lo² ${ }^{2}$ Susan Lau² ${ }^{2}$ Ethan Grober ${ }^{2}$ ${ }^{1}$ Division of Urology, Western University, London, ON, Canada; ${ }^{2}$ Division of Urology, University of Toronto, Toronto, ON, Canada

Cite as: Can Urol Assoc J 2019 July 23; Epub ahead of print. http://dx.doi.org/10.5489/cuaj.5897

Published online July 23, 2019

$* * *$

\section{Abstract}

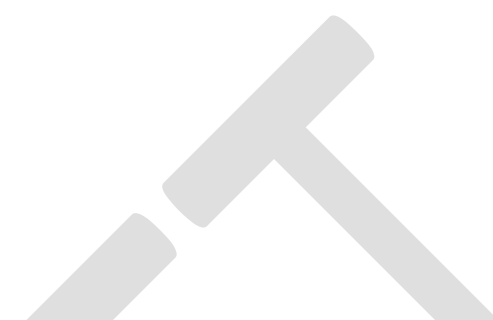

Introduction: We aimed to study the association of ethnicity on semen parameters and hormones in patients presenting with infertility.

Methods: Data from men presenting for infertility assessment were prospectively collected and retrospectively reviewed. Demographic and clinical history was selfreported. Semen analysis included volume, count, motility, morphology, and vitality. The 2010 World Health Organization cutoffs were used. Baseline total testosterone and follicle-stimulating hormone (FSH) levels were recorded. Ethnicity data was classified as Caucasian, African-Canadian, Asian, Indo-Canadian, Native-Canadian, Hispanic, and Middle Eastern. All patients with complete data were included and statistical analysis was performed.

Results: A total of 9079 patients were reviewed, of which 3956 patients had complete data. Of these, 839 (21.2\%) were azoospermic. After adjusting for age, AfricanCanadians (odds ratio [OR] 1.70; 95\% confidence interval [CI] 1.28-2.25) and Asians (1.34; 95\% CI 1.11-1.62) were more likely to be azoospermic compared to Caucasians. Similarly, African Canadians (OR 1.75; 95\% CI 1.33-2.29) were more likely to be oligospermic and Asians (OR 0.82; 95\% CI 0.70-0.97) less likely to be oligospermic. Low volume was found in African-Canadian (OR 1.42; 95\% CI 1.05-1.91), Asians (OR 1.23; 95\% CI 1.01-1.51), and Indo-Canadians (OR 1.47; 95\% CI 1.01-2.13). Furthermore, Asians (OR 0.73; 95\% CI 0.57-0.93) and Hispanics (OR 0.58; 95\% CI 034-0.99) were less likely to have asthenospermia. Asians (OR 0.73; 95\% CI 0.57-0.94) and Indo-Canadians (OR 0.58; 95\% CI 0.35-0.99) were less likely to have teratozospermia. No differences were seen for vitality. No differences were seen for FSH levels, however, Asians $(\mathrm{p}<0.01)$ and Indo-Canadians $(\mathrm{p}<0.01)$ were more likely to have lower testosterone. 
Conclusions: Our study illustrates that variations in semen analyses and hormones exist in men with infertility. This may provide insight into the workup and management for infertile men from different ethnicities.

\section{Introduction}

Male factor infertility is identified in up to $50 \%$ of couples presenting with infertility. ${ }^{1,2}$ The primary investigation for men with infertility is a semen analysis examining semen parameters, used to identify any abnormalities as well as potential avenues for intervention and management. ${ }^{3}$ Along with semen analyses, many patients often complete other investigations including diagnostic imaging and hormonal profiles including serum levels of follicle stimulating hormone (FSH), Luteinizing hormone ( $\mathrm{LH}$ ) and testosterone. $^{4}$

Semen parameters reference ranges were based on the World Health Organization (WHO) standardized semen analysis which were derived from the values of semen parameters from men with known fertility. ${ }^{5}$

The 2010 WHO edition was developed having examined semen quality from fertile men in the general population from a total of fifteen countries on five continents, with the majority from Europe and North America: Australia (Sydney, Melbourne), Europe (Edinburgh, Manchester, Munster, Paris, Turku, Copenhagen, Oslo, Stockholm, Szeged, Bicetre, Bologna) North America (Los Angeles, Columbia, Davis, Seattle), South America (Santiago) and Asia (Singapore, Beijing, Nanjing, Chengdu). ${ }^{5}$ These ranges do not account for potential inherent ethnic and racial influences based on the limited heterogeneity of the reference value population from the WHO 2010 edition, nor the consideration of genetic, environmental or behavioral factors which may vary based on ethnicity. Little is known regarding racial and ethnic disparities for semen parameters and hormones, and has only been examined by very few studies. ${ }^{6}$ These studies have shown some altered concentration, count and volume parameters differences between White and Asian and White and Black men.

Therefore, the goal of our study was to retrospectively review a large database of semen parameters and hormone levels to identify any trends or associations by ethnicity. Our study population is fairly heterogenous in Ontario, Canada, and is therefore useful in studying various ethnicities. This may aid in the initial work-up of these patients with infertility. 


\section{Methods}

Data from Canadian men between 2008 and 2017 presenting for an infertility assessment at a single high-volume referral institution was prospectively collected and retrospectively reviewed. All patients were included who had complete data available for ethnicity, semen analysis and hormonal data. Ethics approval was obtained from the Research Ethics Board at the University of Toronto.

Demographic and clinical history including past medical history, surgical history, medications and infertility history was obtained from a self-reported patient questionnaire. Ethnicities were self-classified as Caucasian, African-Canadian, Asian, Indo-Canadian (from Indian subcontinent), Native-Canadian, Hispanic and Middle Eastern. Secondary infertility was classified based on participants reporting any child age with either their current or previous partner, the remainder were considered to have primary infertility. Duration of infertility was categorized based on patient reported duration of unprotected intercourse (per month). Patients were excluded if they did not report their ethnicity or did not a recorded semen analysis.

Semen analysis data was obtained directly from the Department of Pathology and Laboratory Medicine at our institution using an identical protocol throughout the period of the study. Semen parameters recorded included volume, count, motility, morphology and vitality. Blood work was completed at various laboratories and included FSH and testosterone. Cut-off values were adopted from the 2010 WHO documented reference ranges for semen parameters to define azoospermia (concentration 0 million/ml), oligospermia (concentration $<15 \mathrm{million} / \mathrm{ml}$ ), asthenospermia (motility $<40 \%$ ), teratozospermia (normal morphology $<4 \%$ ), low vitality $(<58 \%)$ and low volume $(<1.5 \mathrm{ml}){ }^{5}$ To limit the influence of previous treatments, only first-time semen analysis and hormone levels were utilized after presentation to the infertility clinic.

Data was analyzed descriptively. Linear regression was used to compare hormonal profile differences between ethnicities. Multivariate logistic regression evaluated the association between ethnicity and with various semen parameters. Models were adjusted for age. Odds ratios were presented with 95\% confidence intervals with significance tested using a two-sided p-value $<0.05$. Statistical analysis was completed using Stata version 14.1.

\section{Results}

A total of 9079 patients were reviewed, of which 3956 patients had documented semen analysis as well as ethnicity data. Patients without these were excluded from the analysis. Table 1 illustrates demographic data for the included patients. Overall median age was 36 (IQR 32-40). The vast majority (3325, 84\%) were non-smokers, and almost half (1745, $44 \%$ ) did not consume any alcohol. 
About half of the patients were Caucasian (2226, 56\%) with Asians representing the second largest group (843, 21\%). Further breakdown of patients by ethnicity is seen in Table 1, which also highlights significant inter-group differences for both demographic and infertility factors. Smoking rates were highest amongst Hispanics, and lowest in Asians and African-Canadians. Alcohol consumption was most prevalent in Caucasians and lowest in Asians and Middle Eastern individuals. Native Canadians, AfricanCanadians and Hispanics were found to have the lowest rates of primary infertility. Intercourse frequency was generally ranged between 7-10 times per month across various ethnicities. Duration of infertility was fairly similar with a median of 24-36 years in all groups.

\section{Semen parameters}

Table 2 illustrates the frequency distribution of patients with abnormal semen parameters according to WHO 2010 criteria. The most common abnormalities seen amongst all ethnicities were asthenospermia ( $n=2658,67 \%)$ and oligospermia $(n=2239,57 \%)$, and least common were teratozospermia $(n=581,15 \%)$, and low vitality ( $n=654,17 \%)$. African-Canadians had the lowest median sperm concentration, with Native Canadians and Hispanics having the highest median sperm concentrations.

Multivariate analysis was completed and illustrated in Table 3. After adjusting for age, we found that African-Canadians (OR 1.70, 95\%CI 1.28-2.25) and Asians (1.34, 95\%CI 1.11-1.62) were more likely to be azoospermic compared to Caucasians. African Canadians (OR 1.75, 95\%CI 1.33-2.29) were more likely to be oligospermic and Asians (OR 0.82, 95\%CI 0.70-0.97) less likely to be oligospermic. Low volume ejaculate was more commonly found in African-Canadians (OR 1.42, 95\%CI 1.05-1.91), Asians (OR 1.23, 95\%CI 1.01-1.51) and Indo-Canadians (OR 1.47, 95\%CI 1.01-2.13) . Furthermore, Asians (OR 0.73, 95\%CI 0.57-0.93) and Hispanics (OR 0.58, 95\%CI 0.34-0.99) were less likely to have asthenospermia. Asians (OR 0.73, 95\%CI 0.57-0.94) and IndoCanadians (OR 0.58, 95\%CI 0.35-0.99) were less likely to have teratozospermia. No differences were seen for vitality.

\section{Hormonal profiles}

Table 2 illustrates the distribution of FSH and total testosterone by ethnicity. AfricanCanadians had both the highest FSH as well as highest total testosterone. Indo-Canadians had the lowest total testosterone, and Middle Eastern individuals had the lowest FSH.

Linear regression for hormones is displayed in Table 4 . When adjusted for age, no differences were seen for FSH levels, however, Asians $(\mathrm{p}<0.01)$ and Indo-Canadians $(\mathrm{p}<0.01)$ were more likely to have lower total testosterone levels. 


\section{Discussion}

Male factor infertility is a significant contributor in the work-up of couples for infertility, and includes semen analysis and serum hormones. Current reference standards are based on the 2010 WHO criteria which has limited accountability for variations in ethnicity. Our study explored the impact of ethnicity on both semen parameters and gonadotropin levels and illustrates differences do exist between ethnicities which may be useful in the work-up and management of these individuals.

Published online demographic statistics of the province of Ontario, Canada in 2016, indicates that approximately one-third of the population (29.3\%) are visible minorities, where our study had $43.7 \%$ were minority groups. ${ }^{7}$ More than half of our study population was Caucasian, followed by Asians, Middle Eastern individuals, and African-Canadians (Table 1). In comparison to the provincial racial distribution, the largest visible minority groups are South Asian (29.6\%), Chinese (19.4\%), Black (16.2\%), Filipino (8.0\%) and Middle Eastern (5.4\%). ${ }^{7}$ Overall this indicates reasonable applicability of our data to the province and the representativeness of our patient population.

Few studies have examined ethnicity correlated to semen parameters. ${ }^{6}$ One study by Redmon et al. which originally looked at geographic variation in the United States, showed poorer semen quality in rural populations, but also looked at Hispanic/Latino, White and Black individuals in further analysis. They studied 557 White men and 57 Black men and found that Blacks had statistically significant lower semen volumes $(p=0.0001)$, concentration $(p=0.009)$ and total sperm counts $(p=0.0001){ }^{6}$ A more recent study by Khandwala et al. has looked at differences between White and Asian in a large cohort of 1230 White men and 701 Asian men and illustrated that differences in concentration $(\mathrm{p}<0.001)$, count $(\mathrm{p}=0.002)$ and volume $(\mathrm{p}<0.0001)$ are present. ${ }^{8}$ Glazer et al. also demonstrated that Asians had the highest sperm concentrations, and Blacks with the lowest, similar to our data. ${ }^{9}$ Furthermore, additional studies have looked at Chinese populations but lack a comparator group, ${ }^{10}$ and Japanese populations with limited sample size of only 324 men. ${ }^{11}$

Our analysis, similar to the data in the study by Redmon et al., even after adjusting for age, showed that African-Canadians were most likely to have more abnormal semen parameters including azoospermia, oligospermia or low volume. Interestingly, Asians, which had been previously reported by Khandwala et al. to have higher rates of azoospermia and higher sperm concentrations, in our study were similarly more likely to be azoospermic, but also improved motility and morphology, and less likely to be simply oligospermic. Indo-Canadians on adjusted analysis were still shown to have decreased rates of teratozospermia. No significant differences in semen parameters or hormones were shown for Middle Eastern individuals, Native-Canadians and 
Hispanics but small differences may not have been identified with the relative small sample sizes of these groups in our study.

In our study, we found that Asians and Indo-Canadians were more likely to have lower testosterone levels and no differences were seen for FSH in our adjusted analysis. Many studies in the literature investigating hormonal profiles between patients have been completed in the prostate cancer sub-population or in adolescents. ${ }^{12,13}$ One study in adolescents showed Mexican-Americans to have the highest testosterone compared to non-Hispanic Whites, and non-Hispanic Blacks ${ }^{12}$ and another showed that Blacks had a higher level of testosterone only in the age category $20-39 .^{14}$ While some studies have shown no difference, ${ }^{15}$ a recent meta-analysis compared sex-steroid hormone concentration in black and white men and found that black men had a slightly significant higher level of free testosterone. ${ }^{16}$

Identified racial differences in semen parameters and hormones may be genetic, due to sociodemographic factors but also due to dietary and/or cultural differences. Certain explanations may include less time before seeking fertility treatments which may dilute the population with more normal parameters, or perhaps certain cultures do not even present for fertility evaluations out of fear, shame or religious concerns, or even various environmental/dietary exposures that may be cultural in nature. ${ }^{17,18}$ The underrepresentation of certain minority groups may also be due to financial burdens, given the cost of many assisted reproductive technologies. ${ }^{19}$ Recent work has also highlighted semen quality differences based on various sociodemographic factors including race, education, and geographic location in the United States. ${ }^{9}$ However, in a Canadian healthcare system there is likely less resource accessibility and financial barriers than one would expect in a private system. ${ }^{20}$ With respect to hormonal differences some theories may relate to variable genetics of hormone metabolism, or lifestyle factors that may differ by ethnicity. ${ }^{16,21}$

The clinical implications of this are important as it may alter patient management, for example in deciding which patients would be more likely to benefit from hormonal manipulation.

Limitations of our study do include the retrospective nature and self-reported patient questionnaire for demographic data which may lead to misclassification and recall bias. Therefore, data related to immigration and other socioeconomic variables not included in the questionnaire were not available. There is variation of serum hormone levels as results were obtained from numerous laboratories. However, the sample size is large, and includes all patients seen for infertility at a specialized center. The semen analysis data is robust in that it is uses a single lab increasing reliability and comparability. Only first-time semen analyses were included to reduce any bias from any 
treatments or intervention. Finally, all patients were included from the same geographic region to reduce any environmental bias and minimize variation.

\section{Conclusions}

Currently global thresholds for male infertility are based on the 2010 WHO standards, however, racial and ethnic differences may exist. Our study illustrates that within Canadian men, which represent a diverse population, who present for male infertility, that differences in semen analysis and hormones are present. An understanding of this variation may aid in the counselling and work-up of these patients. Further validation and assessment of current references is required in large and varying populations, to help understand the potential genetic, environmental, behavioral and cultural patters that may explain these differences. 


\section{References}

1. Kumar N, Singh AK. Trends of male factor infertility, an important cause of infertility: A review of literature. Journal of human reproductive sciences 2015;8:191-6.

2. Nayan M, Punjani N, Grober E, et al. The use of reproductive technology before male factor infertility evaluation. Translational Andrology and Urology 2018.

3. Brugh VM, 3rd, Lipshultz LI. Male factor infertility: Evaluation and management. The Medical clinics of North America 2004;88:367-85.

4. Bhasin S. Approach to the infertile man. The Journal of clinical endocrinology and metabolism 2007;92:1995-2004.

5. Cooper TG, Noonan E, von Eckardstein S, et al. World health organization reference values for human semen characteristics. Human reproduction update 2010;16:231-45.

6. Redmon JB, Thomas W, Ma W, et al. Semen parameters in fertile us men: The study for future families. Andrology 2013;1:806-14.

7. Finance Mo. Census highlights - ethnic origin and visible minorities. In: Ontario Go, editor. 2016.

8. Khandwala YS, Zhang CA, Li S, et al. Racial variation in semen quality at fertility evaluation. Urology 2017;106:96-102.

9. Glazer CH, Li S, Zhang CA, et al. Racial and sociodemographic differences of semen parameters among us men undergoing a semen analysis. Urology 2019;123:126-32.

10. Gao J, Gao ES, Walker M, et al. Reference values of semen parameters for healthy chinese men. Urologia internationalis 2008;81:256-62.

11. wamoto T, Nozawa S, Yoshiike M, et al. Semen quality of 324 fertile japanese men. Human reproduction 2006;21:760-5.

12. Lopez DS, Peskoe SB, Joshu CE, et al. Racial/ethnic differences in serum sex steroid hormone concentrations in us adolescent males. Cancer causes \& control : CCC 2013;24:817-26.

13. Kubricht WS, 3rd, Williams BJ, Whatley T, et al. Serum testosterone levels in african-american and white men undergoing prostate biopsy. Urology 1999;54:1035-8.

14. Hu H, Odedina FT, Reams RR, et al. Racial differences in age-related variations of testosterone levels among us males: Potential implications for prostate cancer and personalized medication. Journal of racial and ethnic health disparities 2015;2:69-76.

15. Ellis L, Nyborg H. Racial/ethnic variations in male testosterone levels: A probable contributor to group differences in health. Steroids 1992;57:72-5.

16. Richard A, Rohrmann S, Zhang L, et al. Racial variation in sex steroid hormone concentration in black and white men: A meta-analysis. Andrology 2014;2:42835.

17. Guzzo KB, Nash SP, Manning WD, et al. Unpacking the "black box" of raceethnic variation in fertility. Race and social problems 2015;7:135-49. 
18. Hayford SR, Morgan SP. Religiosity and fertility in the united states: The role of fertility intentions. Social forces; a scientific medium of social study and interpretation 2008;86:1163-88.

19. Farland LV, Collier AY, Correia KF, et al. Who receives a medical evaluation for infertility in the united states? Fertility and sterility 2016;105:1274-80.

20. Armstrong A, Plowden TC. Ethnicity and assisted reproductive technologies. Clinical practice 2012;9:651-8.

21. Ahn J, Schumacher FR, Berndt SI, et al. Quantitative trait loci predicting circulating sex steroid hormones in men from the nci-breast and prostate cancer cohort consortium (bpc3). Human molecular genetics 2009;18:3749-57. 


\section{Figures and Tables}

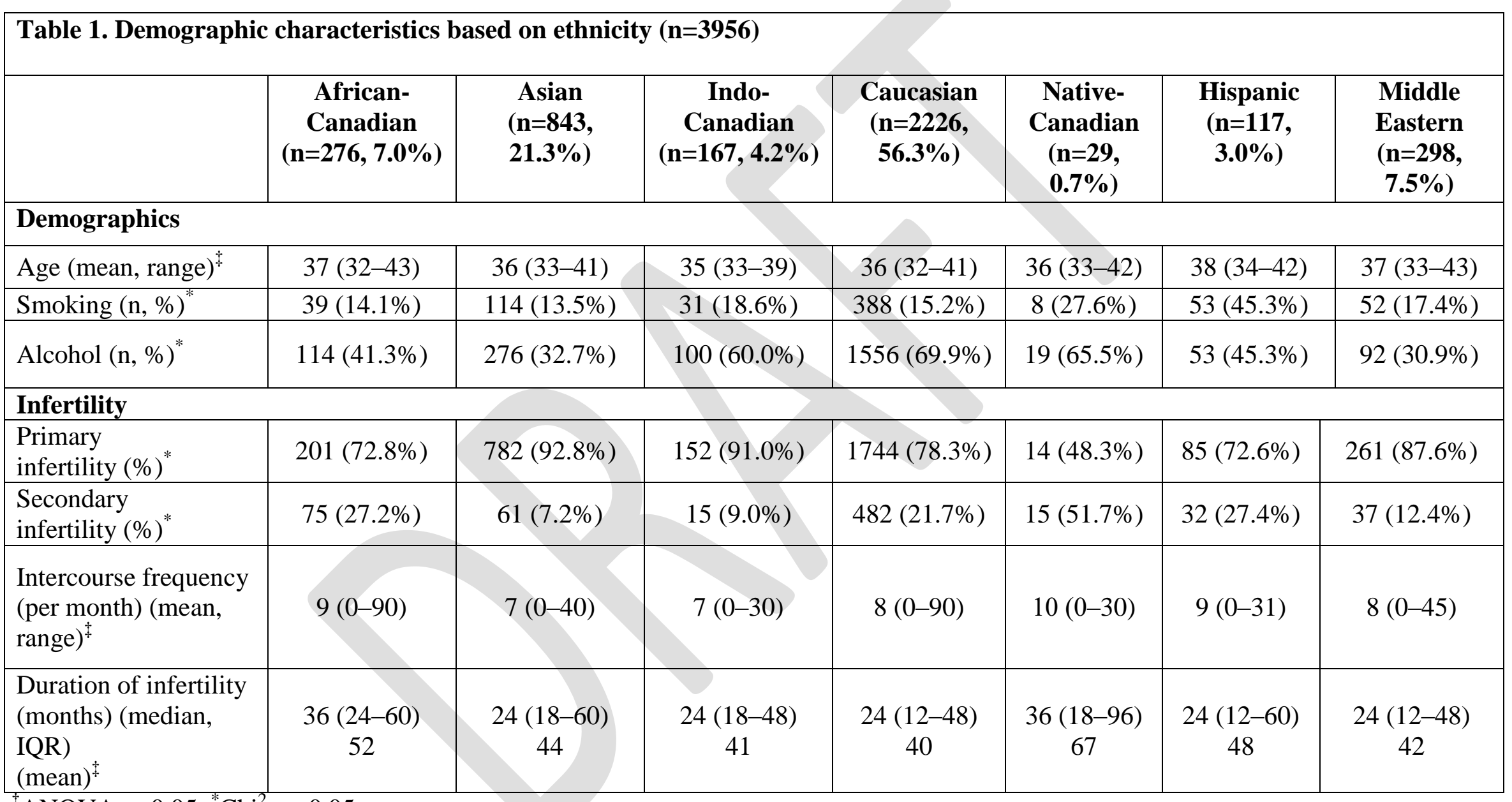

${ }^{\mp}$ ANOVA $\mathrm{p}<0.05 .{ }^{*} \mathrm{Chi}^{2} \mathrm{p}<0.05$. 


\begin{tabular}{|c|c|c|c|c|c|c|c|}
\hline & $\begin{array}{c}\text { African- } \\
\text { Canadian } \\
(\mathbf{n}=276, \\
7.0 \%)\end{array}$ & $\begin{array}{c}\begin{array}{c}\text { Asian } \\
(n=843, \\
21.3 \%)\end{array}\end{array}$ & $\begin{array}{c}\text { Indo- } \\
\text { Canadian } \\
(\mathrm{n}=167, \\
4.2 \%)\end{array}$ & $\begin{array}{c}\text { Caucasian } \\
(n=2226, \\
56.3 \%)\end{array}$ & $\begin{array}{c}\text { Native- } \\
\text { Canadian } \\
(\mathbf{n}=29 \\
\mathbf{0 . 7 \%})\end{array}$ & $\begin{array}{c}\text { Hispanic } \\
(\mathrm{n}=117 \\
3.0 \%)\end{array}$ & $\begin{array}{c}\text { Middle } \\
\text { Eastern } \\
(\mathbf{n}=298, \\
7.5 \%)\end{array}$ \\
\hline \multicolumn{8}{|c|}{ Semen parameters } \\
\hline $\begin{array}{l}\text { Concentration } \\
\text { (million/ml) } \\
\text { (median, IQR) }\end{array}$ & $\begin{array}{c}5.3 \\
(0.0-24.8)\end{array}$ & $\begin{array}{c}13.4 \\
(0.1-13.4)\end{array}$ & $\begin{array}{c}11.2 \\
(0.4-51.9)\end{array}$ & $\begin{array}{c}9.5 \\
(0.5-35.7)\end{array}$ & $\begin{array}{c}17.6 \\
(0.0-38.2)\end{array}$ & $\begin{array}{c}19.4 \\
(0.4-63.5)\end{array}$ & $\begin{array}{c}8.15 \\
(0.3-25.1)\end{array}$ \\
\hline $\begin{array}{l}\text { Motility (\%) } \\
\text { (median, IQR) }\end{array}$ & $\begin{array}{c}19.2 \\
(9.6-29.0)\end{array}$ & $\begin{array}{c}25.1 \\
(13.6-34.2)\end{array}$ & $\begin{array}{c}24.4 \\
(14.0-34.3)\end{array}$ & $\begin{array}{c}24.1 \\
(14.3-32.9)\end{array}$ & $\begin{array}{c}15.5 \\
(12.5-26.7)\end{array}$ & $\begin{array}{c}29.8 \\
(16.7-38.1)\end{array}$ & $\begin{array}{c}21.5 \\
(11.7-31.6)\end{array}$ \\
\hline $\begin{array}{l}\text { Volume (ml) } \\
\text { (median, IQR) }\end{array}$ & $\begin{array}{c}2.0 \\
(1.5-3.0)\end{array}$ & $\begin{array}{c}2.5 \\
(1.5-3.5)\end{array}$ & $\begin{array}{c}2.0 \\
(1.5-3.0)\end{array}$ & $\begin{array}{c}2.5 \\
(1.5-3.5)\end{array}$ & $\begin{array}{c}2.5 \\
(1.5-3.5)\end{array}$ & $\begin{array}{c}2.5 \\
(1.5-3.5)\end{array}$ & $\begin{array}{c}2.5 \\
(2.0-4.0)\end{array}$ \\
\hline $\begin{array}{l}\text { Morphology (\%) } \\
\text { (median, IQR) }\end{array}$ & $\begin{array}{c}10 \\
(5-15)\end{array}$ & $\begin{array}{c}10 \\
(5-20)\end{array}$ & $\begin{array}{c}10 \\
(5-20)\end{array}$ & $\begin{array}{c}10 \\
(5-15)\end{array}$ & $\begin{array}{c}5 \\
(0-15)\end{array}$ & $\begin{array}{c}10 \\
(5-20)\end{array}$ & $\begin{array}{c}5 \\
(5-15)\end{array}$ \\
\hline $\begin{array}{l}\text { Vitality (\%) } \\
\text { (median, IQR) }\end{array}$ & $\begin{array}{c}70 \\
(50-70) \\
\end{array}$ & $\begin{array}{c}70 \\
(55-75) \\
\end{array}$ & $\begin{array}{c}65 \\
(55-75) \\
\end{array}$ & $\begin{array}{c}70 \\
(60-80) \\
\end{array}$ & $\begin{array}{c}75 \\
(65-85) \\
\end{array}$ & $\begin{array}{c}70 \\
(55-75)\end{array}$ & $\begin{array}{c}70 \\
(60-80)\end{array}$ \\
\hline \multicolumn{8}{|c|}{ Semen parameters (per WHO) } \\
\hline $\begin{array}{l}\text { Azoospermia } \\
(\mathrm{n}=839) \\
(\mathrm{n}, \%)\end{array}$ & $78(28.3 \%)$ & $203(24.1 \%)$ & $33(19.8 \%)$ & 428 (19.2\%) & $8(27.6 \%)$ & $24(20.5 \%)$ & $65(21.8 \%)$ \\
\hline $\begin{array}{l}\text { Oligospermia } \\
(\mathrm{n}=2239) \\
(\mathrm{n}, \%) \\
\end{array}$ & $190(68.8 \%)$ & 437 (51.8\%) & $90(53.9 \%)$ & $1269(57.0 \%)$ & $14(48.3 \%)$ & $57(48.7 \%)$ & $182(61.1)$ \\
\hline $\begin{array}{l}\text { Asthenospermia } \\
(\mathrm{n}=2658) \\
(\mathrm{n}, \%)\end{array}$ & $180(65.2 \%)$ & 530 (62.9\%) & $109(65.3 \%)$ & $1549(69.6 \%)$ & $19(65.5 \%)$ & $74(63.2 \%)$ & $197(66.1 \%)$ \\
\hline
\end{tabular}


Effect of ethnicity on semen and hormonal parameters

\begin{tabular}{|l|c|c|c|c|c|c|c|}
\hline $\begin{array}{l}\text { Teratozoospermia } \\
(\mathrm{n}=581) \\
(\mathrm{n}, \%)\end{array}$ & $39(14.1 \%)$ & $99(11.7 \%)$ & $17(10.2 \%)$ & $353(15.9 \%)$ & $8(27.6 \%)$ & $13(11.1 \%)$ & $52(17.4 \%)$ \\
\hline $\begin{array}{l}\text { Low volume } \\
(\mathrm{n}=748) \\
(\mathrm{n}, \%)\end{array}$ & $67(24.3 \%)$ & $176(20.9 \%)$ & $39(23.4 \%)$ & $386(17.3 \%)$ & $7(24.1 \%)$ & $27(23.1 \%)$ & $49(16.4 \%)$ \\
\hline $\begin{array}{l}\text { Poor vitality } \\
(\mathrm{n}=654) \\
(\mathrm{n}, \%)\end{array}$ & $51(18.5 \%)$ & $147(17.4 \%)$ & $30(18.0 \%)$ & $353(15.9 \%)$ & $5(17.2 \%)$ & $13(11.1 \%)$ & $55(18.5 \%)$ \\
\hline Hormones & $5.9(3.6-10)$ & $5.5(3.5-10)$ & $4.8(3.3-8.3)$ & $5.5(3.5-10)$ & $6.0(4.3-12)$ & $5.6(3.8-8.8)$ & $5.1(3.1-9.0)$ \\
\hline $\begin{array}{l}\text { FSH } \\
(m e d i a n, ~ I Q R)\end{array}$ & $13(11-17)$ & $11(8.4-16)$ & $9.9(8.4-14)$ & $13(9.6-17)$ & $13(11-16)$ & $13(8.7-16.5)$ & $12(9.4-16)$ \\
\hline $\begin{array}{l}\text { Testosterone } \\
(m e d i a n, ~ I Q R)\end{array}$
\end{tabular}

IQR: interquartile range. 


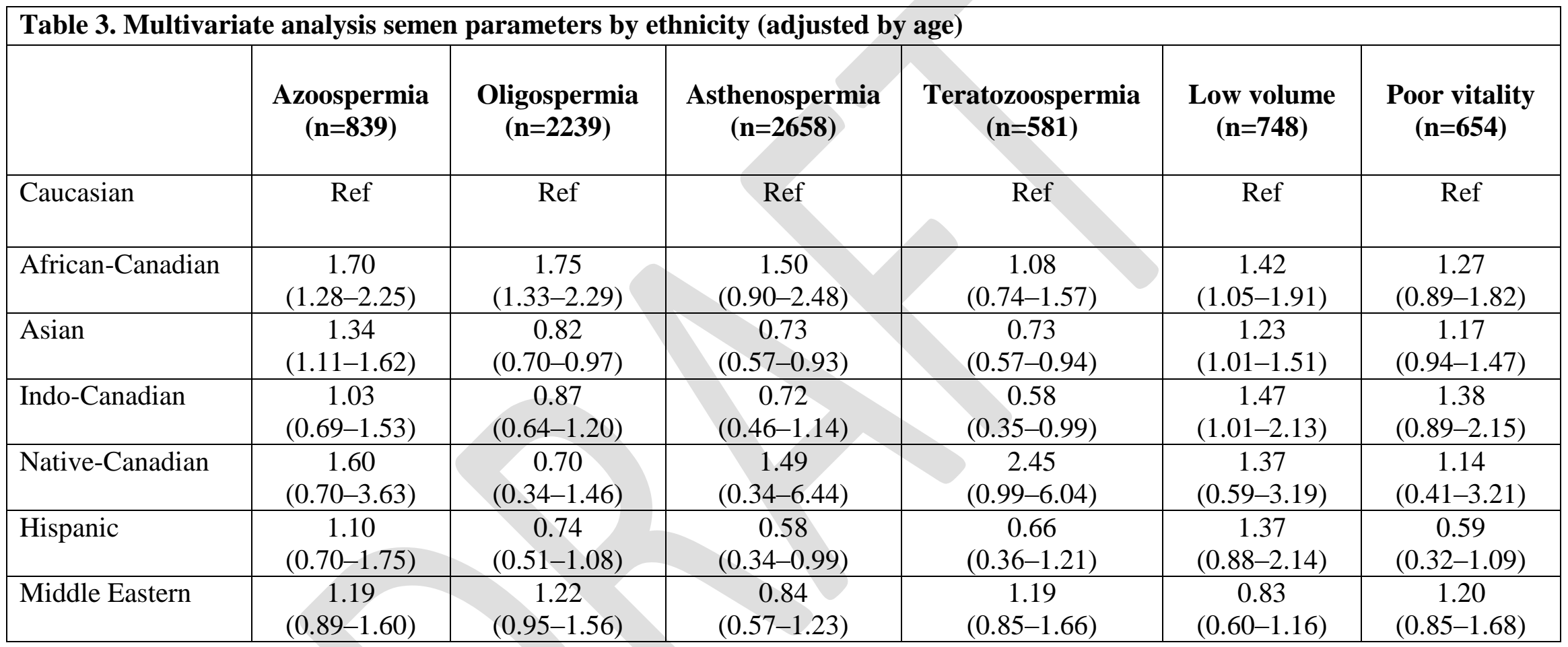


Table 4. Linear regression for hormone profiles by ethnicity (adjusted by age)

\begin{tabular}{|l|c|c|}
\hline & FSH & Testosterone \\
\hline Caucasian & Ref & Ref \\
\hline African-Canadian & 0.49 & 0.55 \\
& $(-0.68-1.66)$ & $(-0.22-1.32)$ \\
\hline Asian & -0.07 & -1.26 \\
& $(-0.85-0.70)$ & $(-1.77-(-0.76))$ \\
\hline Indo-Canadian & -1.38 & -1.92 \\
& $(-2.82-0.04)$ & $(-2.85-(-0.99))$ \\
\hline Native-Canadian & 1.65 & -1.43 \\
& $(-1.37-4.67)$ & $(-3.38-0.52)$ \\
\hline Hispanic & 0.23 & -0.47 \\
& $(-1.79-2.24)$ & $(-1.78-0.84)$ \\
\hline Middle Eastern & -0.78 & -0.59 \\
& $(-1.94-0.38)$ & $(-1.35-0.17)$ \\
\hline
\end{tabular}

FSH: follicle-stimulating hormone. 